\title{
Monoamine acid metabolites and cerebrospinal fluid dynamics in normal pressure hydrocephalus: preliminary results
}

\author{
G. MAIRA, S. R. BAREGGI, C. DI ROCCO, G. CALDERINI, AND \\ P. L. MORSELLI ${ }^{1}$ \\ From Istituto di Neurochirurgia, Università Cattolica del Sacro Cuore, Rome, and \\ Istituto di Ricerche Farmacologiche 'Mario Negri', Milano, Italy
}

SYNOPSIS Lumbar and ventricular CSF concentration of homovanillic acid (HVA) and 5-hydroxyindole-acetic acid (5-HIAA) have been determined in 13 patients admitted to hospital for suspected normal pressure hydrocephalus. Low values of HVA in lumbar CSF were found in all patients with reduced CSF absorption and CSF flow inversion. The HVA lumbar concentration remained low after shunt procedure; it increased if obstruction of the shunt occurred. The ventricular CSF concentration of HVA was normal before surgery; it became higher, in two cases, after surgery. No important variations were found in the lumbar and ventricular CSF concentration of 5-HIAA. The possible mechanisms and diagnostic value of these findings are discussed.

Normal pressure hydrocephalus (Adams et al., 1965; Hakim and Adams, 1965) is a syndrome clinically characterized by a subacute onset of a progressive global psychological deterioration and gait disturbances, with or without urinary incontinence. The clinical syndrome is associated with increased ventricular size and normal intracranial pressure (ICP). Brain trauma, subarachnoid bleeding, intracranial infection, cranial surgery, and ectasia of the basilar artery have been recognized as the most frequent aetiological factors. The syndrome can be found also in patients with an apparently negative clinical history. A defect in the absorption of cerebrospinal fluid (CSF) has been postulated as the mechanism for the development of such a syndrome (Lorenzo et al., 1970b). This assumption is partially sustained by the results of diagnostic procedures and by the efficacy of surgical CSF shunt in a relevant number of cases. Rossi et al. (1974) have recently shown that none of the diagnostic procedures commonly employed to define the syndrome

\footnotetext{
${ }^{1}$ Address for correspondence: Dr. P. L. Morselli, Istituto di Ricerche Farmacologiche 'Mario Negri', Via Eritrea, 62, Milano, Italy.

(Accepted 13 August 1974.)
}

(pneumoencephalography and isotope-cisternography) could by itself provide satisfactory information with prognostic value for surgical treatment.

Andersson and Roos $(1966,1969)$ found that CSF concentration of 5-hydroxy-indole-acetic acid (5-HIAA) was altered in hydrocephalic children and suggested a possible diagnostic value for such a determination. A decreased lumbar CSF concentration of homovanillic acid (HVA) was observed (Porta et al., 1973: Bareggi et al., 1975) in patients suffering from chronic syndromes after a severe head injury and (Edvinsson et al., 1972) in hydrocephalic rabbits.

On the basis of these findings it was thought interesting to evaluate the lumbar and ventricular CSF concentration of 5-HIAA and HVA in patients suffering from normal pressure hydrocephalus. We report here some preliminary observations suggesting that determination of HVA concentrations in the CSF of these patients may provide useful information on CSF dynamics and may also have a diagnostic value.

\section{METHODS}

SUBJECTS Observations were performed on 13 patients (11 males and two females) admitted to the 
TABLE 1

CLINICAL DATA AND LUMBAR CSF HVA AND 5-HIAA LEVELS IN NORMOTENSIVE

\begin{tabular}{|c|c|c|c|c|c|c|c|c|c|c|}
\hline \multirow{2}{*}{$\begin{array}{l}\text { Case } \\
\text { no. }\end{array}$} & \multirow{2}{*}{$\begin{array}{l}\text { Age } \\
(y r)\end{array}$} & \multirow{2}{*}{ Sex } & \multicolumn{3}{|c|}{$\begin{array}{c}\text { Clinical } \\
\text { evaluation }\end{array}$} & \multirow[b]{2}{*}{$R I S A \dagger$} & \multirow{2}{*}{$\begin{array}{c}\mathbf{I}^{131} \\
\text { haematic } \\
\text { absorption } \ddagger\end{array}$} & \multirow{2}{*}{$\begin{array}{c}\text { Katzman's } \\
\text { test } \S\end{array}$} & \multirow{2}{*}{$\begin{array}{c}I C P \\
(m m ~ H g)\end{array}$} & \multirow{2}{*}{$\begin{array}{l}\text { Ventricular } \\
\text { dilatation }\end{array}$} \\
\hline & & & $P D$ & $G D$ & $P S$ & & & & & \\
\hline $\begin{array}{ll}1 & \text { I.I. } \\
2 & \text { P.L. } \\
3 & \text { N.S. } \\
4 & \text { P.R. } \\
5 & \text { Z.G. } \\
6 & \text { B.B. } \\
7 & \text { L.V.A. } \\
8 & \text { S.V. }\end{array}$ & $\begin{array}{l}32 \\
33 \\
42 \\
59 \\
42 \\
57 \\
27 \\
51\end{array}$ & $\begin{array}{l}\mathbf{M} \\
\mathbf{M} \\
\mathbf{M} \\
\mathbf{M} \\
\mathbf{M} \\
\mathbf{F} \\
\mathbf{M} \\
\mathbf{F}\end{array}$ & $\begin{array}{l}+ \\
+ \\
+ \\
+ \\
+ \\
+ \\
+ \\
+\end{array}$ & $\begin{array}{l}- \\
+ \\
+ \\
+ \\
+ \\
+ \\
+\end{array}$ & $\begin{array}{l}- \\
\pm \\
- \\
+ \\
+ \\
+\end{array}$ & $\begin{array}{l}\mathbf{B}_{1} \\
\mathbf{B}_{1} \\
\mathbf{B}_{2} \\
\mathbf{B}_{2} \\
\mathbf{B}_{2} \\
\mathbf{B}_{2} \\
\mathbf{B}_{2} \\
\mathbf{B}_{2}\end{array}$ & $\begin{array}{l}\mathbf{N} \\
\mathbf{N} \\
\mathbf{N} \\
\mathbf{N} \\
\mathbf{N} \\
\mathbf{N} \\
\mathbf{N} \\
\mathbf{N}\end{array}$ & $\begin{array}{l}+ \\
+ \\
+ \\
+ \\
+ \\
+ \\
+ \\
+\end{array}$ & $\begin{array}{l}13.0 \\
15.2 \\
11.1 \\
10.3 \\
12.72 \\
6.10 \\
12.5 \\
13.2\end{array}$ & $\begin{array}{l}+ \\
+ \\
+ \\
+ \\
+ \\
+ \\
+ \\
+\end{array}$ \\
\hline $\begin{aligned} 9 & \text { S.S. } \\
10 & \text { P.S. } \\
11 & \text { F.A. } \\
12 & \text { P.G. } \\
13 & \text { F.Q. }\end{aligned}$ & $\begin{array}{l}65 \\
55 \\
38 \\
37 \\
46\end{array}$ & $\begin{array}{l}\mathbf{M} \\
\mathbf{M} \\
\mathbf{M} \\
\mathbf{M} \\
\mathbf{M}\end{array}$ & $\begin{array}{l}+ \\
+ \\
\pm \\
+ \\
+\end{array}$ & $\begin{array}{l}+ \\
+ \\
\pm \\
\pm \\
\pm\end{array}$ & $\begin{array}{l}\bar{z} \\
\bar{z}\end{array}$ & $\begin{array}{l}\mathbf{B}_{3} \\
\mathbf{B}_{3} \\
\mathrm{~A} \\
\mathbf{B}_{3} \\
\mathbf{B}_{3}\end{array}$ & $\begin{array}{l}N \\
N \\
D \\
\bar{N}\end{array}$ & $\begin{array}{l}\bar{z} \\
\bar{z} \\
\overline{N P}\end{array}$ & $\begin{array}{r}15 \\
10 \\
3 \\
15 \\
6\end{array}$ & $\begin{array}{l}+ \\
+ \\
+ \\
+ \\
+\end{array}$ \\
\hline 9 Controls & $\begin{array}{r}27 \\
\pm 6\end{array}$ & & & & & - & - & - & - & - \\
\hline
\end{tabular}

*PD: psychic deterioration. GD: gait disturbances. PS: pyramidal signs.

$+B_{1}$ and $B_{2}$ : massive and manifest ventricular isotope filling. $B_{3}$ : poor filling. A: istotope stopped at cisterna magna.

$\ddagger N$ : normal. D: decreased.

$\S+$ : pathological. - : normal.

P: performed. NP: not performed.

$\mathbf{P}<0.05$ compared with controls.

Department of Neurosurgery of the University Cattolica, Rome, for suspected normal pressure hydrocephalus. A previous traumatic head injury was present in the history of cases $1,2,3,4,9,10,11$, and 12; an endocranial infective process in case 5 , and a subarachnoid haemorrhage due to ruptured aneurysm in case 6 . For cases 7,8 , and 13 , no clear aetiological factor was apparent. In all cases, the intracranial pressure (ICP) was within the normal range both at lumbar and at ventricular level. Pneumoencephalography (PEG) and evaluation of CSF dynamics (RISA) and absorption ( ${ }^{131}$ haematic absorption and lumbar spinal infusion test) were performed as previously described in detail (Galli et al., 1973; Rossi et al., 1974). From these tests, cases 1 to 8 were considered to be typical normal pressure hydrocephalus. With the exception of case 8, who refused surgery, they underwent ventriculoatrial CSF shunt. For the other cases no clear evidence of normal pressure hydrocephalus was present and the patients were therefore discharged from the hospital. However on readmission some months later, for a worsening of the clinical picture, a modification of the diagnostic tests (RISA type $B_{2}$ - see Rossi et al. (1974) - and positive Katzman's test) suggested the necessity for surgical intervention in cases $9,10,11$, and 13 .

BIOCHEMICAL ANALYSIS Lumbar CSF was sampled during diagnostic procedures before shunt operation in 12 patients (cases 1 to 12) and after shunt operation in seven patients (cases 1, 2, 3, 9, 10,11, and 13) (Tables 1 and 4). Ventricular CSF was collected from a catheter, inserted in the lateral ventricle for $\mathrm{ICP}^{\circ}$ monitoring, a few days before the shunt procedureo in cases $1,2,3$, and 10, and from the Pudenz chamber,? several days after the shunt was completed, in cases 2, 3, 9, and 10 (Table 2). CSF samples were immediately frozen at $-60^{\circ} \mathrm{C}$, and kept frozen until analysis. HVA and 5-HIAA were estimated according to Korf et al. (1971) with minor modifications.

Control lumbar CSF samples were obtained from nine patients suspected of intervertebral disc hernia whose diagnosis was proved negative by radiculography.

\section{RESULTS}

LUMBAR CSF CONCENTRATIONS OF HVA AND 5-HIAA BEFORE SHUNT On the basis of the concentrations of monoamine acid metabolites and the diagnostic procedures that were carried out, the patients included in this study can be divided into two distinct groups (Table 1).

Group 1 In the first group (cases 1 to 8 ) lumbar CSF concentrations of HVA ranged from 5 to $13.6 \mathrm{ng} / \mathrm{ml}$, with a mean value of $7.5 \pm 1.2 \mathrm{ng} / \mathrm{ml}$, which was significantly $(\mathrm{P}<0.001)$ lower than those recorded in 
- continued

HYDROCEPHALIC PATIENTS BEFORE SHUNT PROCEDURE

\begin{tabular}{|c|c|c|c|}
\hline $\begin{array}{c}H V A \\
(n g / m l)\end{array}$ & $\begin{array}{r}5-H I A A \\
(n g / m l)\end{array}$ & $\frac{5-H I A A}{H V A}$ & $\begin{array}{c}C S F \\
\text { shunt } \\
\text { procedure }\end{array}$ \\
\hline $\begin{array}{r}9.0 \\
5.0 \\
13.6 \\
12.0 \\
5.0 \\
5.0 \\
5.4 \\
5.0 \\
7.5 \\
+1.26 \\
126.0 \\
53.0 \\
65.2 \\
26.4 \\
N P \\
63.0 \\
+14.8 \\
46.3 \\
\pm 4.9\end{array}$ & $\begin{array}{r}12.1 \\
23.1 \\
56.1 \\
41.5 \\
18.5 \\
20.9 \\
4.5 \\
33.3 \\
26.2 \\
\pm 5.9 \\
26.0 \\
31.0 \\
48.2 \\
17.9 \\
\text { NP } \\
29.6 \\
\pm 5.1 \\
30.0 \\
\pm 3.3\end{array}$ & $\begin{array}{r}1.3 \\
3.4 \\
4.2 \\
3.5 \\
3.7 \\
4.2 \\
0.9 \\
6.6 \\
3.4 \\
\pm 0.6 \\
0.2 \\
0.6 \\
0.7 \\
0.6 \\
N P \\
0.5 \\
\pm 0.1 \\
0.6 \\
\pm 0.1\end{array}$ & 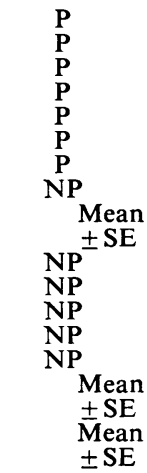 \\
\hline
\end{tabular}

controls $(46.3 \pm 4.9 \mathrm{ng} / \mathrm{ml})$. No differences were, on the other hand, observed for the 5-HIAA concentrations $(26.2 \pm 5.9 \mathrm{ng} / \mathrm{ml})$ with respect to controls $(30.3 \pm 3.3 \mathrm{ng} / \mathrm{ml})$. The mean 5 -HIAA/ HVA ratio was in this group $3.4 \pm 0.6$.

These patients presented also a massive or well manifest ventricular filling (type $B_{1}$ and $B_{2}$ of
Rossi et al., 1974) on isotope cisternography, a normal isotope haematic absorption curve, and a positive Katzman's test. The data suggested that in these cases the ventricular system replaced the subarachnoid spaces for the CSF absorption in basal conditions.

Group 2 In the second group (cases 9 to 13) lumbar CSF HVA concentrations ranged from 26.4 to $126.0 \mathrm{ng} / \mathrm{ml}$, with a mean value of $63 \pm 14.8 \mathrm{ng} / \mathrm{ml}$, which did not differ from that observed in the control group. Lumbar CSF concentrations of 5-HIAA $(29.6 \pm 5.1 \mathrm{ng} / \mathrm{ml})$ were also within control values.

In these patients isotope cisternography showed a poor ventricular filling or an arrest at the cisterna magna (type B3 and A of Rossi et al., 1974); isotope haematic absorption curve (with the exception of case 11) and Katzman's test were normal, indicating that the CSF circulation was not qualitatively altered but only slower than normal.

VENTRICULAR CSF CONCENTRATION OF HVA AND 5-HIAA BEFORE AND AFTER SHUNT PROCEDURE The ventricular concentration of HVA and 5-HIAA found before the shunt procedure is reported in Table 2. HVA and 5-HIAA levels in the patients examined (cases 1, 2, 3, and 10) ranged respectively from 162 to 251 and from 51 to $191 \mathrm{ng} / \mathrm{ml}$. The mean values $(206 \pm 24$ for HVA and $107 \pm 31$ for 5-HIAA) did not differ

TABLE 2

VENTRICULAR CSF CONCENTRATIONS OF HVA AND 5-HIAA IN NORMOTENSIVE HYDROCEPHALUS BEFORE AND AFTER SHUNT-PROCEDURE

\begin{tabular}{|c|c|c|c|c|c|c|}
\hline \multirow{2}{*}{$\begin{array}{l}\text { Case } \\
\text { no. }\end{array}$} & \multirow{2}{*}{$\begin{array}{c}\text { Days } \\
\text { after } \\
\text { shunt } \\
\text { procedure }\end{array}$} & \multicolumn{2}{|c|}{$\begin{array}{c}I C P^{*} \\
(m m H g)\end{array}$} & \multirow{2}{*}{$\begin{array}{c}H V A \\
(n g / m l)\end{array}$} & \multirow{2}{*}{$\begin{array}{c}5-H I A A \\
(n g / m l)\end{array}$} & \multirow{2}{*}{$\frac{5-H I A A}{H V A}$} \\
\hline & & Mean & Pulsing & & & \\
\hline $\begin{array}{l}1 \text { I.I. } \\
2 \text { P.L. } \\
3 \text { N.S. } \\
9 \text { S.S } \\
10 \text { P.S. } \\
\text { Controls } \\
\text { (mean } \pm \text { SE) }\end{array}$ & $\begin{array}{r}0 \\
0 \\
215 \\
0 \\
110 \\
180 \\
0 \\
200\end{array}$ & $\begin{array}{c}13.0 \\
15.0 \\
10 \dagger \\
11.0 \\
8 \dagger \\
3.6 \\
10.0 \\
4.4 \\
5.1 \ddagger \\
\pm 1.3\end{array}$ & $\begin{array}{r}5.0 \\
7.5 \\
3 \\
0.3 \\
4.0 \\
2.9\end{array}$ & $\begin{array}{l}162 \\
251 \\
416 \\
245 \\
127 \\
267 \\
166 \\
338 \\
232 \ddagger \\
\pm 35\end{array}$ & $\begin{array}{r}72 \\
191 \\
74 \\
51 \\
69 \\
84 \\
115 \\
79 \\
80 \ddagger \\
+10\end{array}$ & $\begin{array}{l}0.44 \\
0.76 \\
0.17 \\
0.19 \\
0.54 \\
0.31 \\
0.67 \\
0.27 \\
0.30 \ddagger \\
\pm 0.16\end{array}$ \\
\hline
\end{tabular}

*ICP is ventricular pressure. t: lumbar pressure.

Mean values before shunt: $\mathrm{HVA}=206+24 ; 5$-HIAA $=107+31 ; 5$-HIAA/HVA $=0.51+0.15$.

Mean values after shunt: $\mathrm{HVA}=287 \pm 61 ; 5$-HIAA $=76 \pm 3 ; 5$-HIAA/HVA $=0.31 \pm 0.08$.

†From West et al. (1972). 
TABLE 3

RELATIONSHIPS BETWEEN VENTRICULAR AND LUMBAR CSF CONCENTRATIONS OF HVA AND 5-HIAA IN NORMAL PRESSURE HYDROCEPHALUS BEFORE AND AFTER SHUNT PROCEDURE

\begin{tabular}{|c|c|c|c|c|c|c|c|}
\hline \multirow{2}{*}{$\begin{array}{l}\text { Case } \\
\text { no. }\end{array}$} & \multirow{2}{*}{$\begin{array}{c}\text { Days after } \\
\text { shunt }\end{array}$} & \multicolumn{3}{|c|}{$H V A(n g / m l)$} & \multicolumn{3}{|c|}{ 5-HIAA (ng/ml) } \\
\hline & & $V$ & $L$ & $V / L$ & $V$ & $L$ & $V / L$ \\
\hline $\begin{aligned} 1 & \text { I.I. } \\
2 & \text { P.L. } \\
3 & \text { N.S. } \\
9 & \text { S.S. } \\
10 & \text { P.S. }\end{aligned}$ & $\begin{array}{r}0 \\
0 \\
216 \\
0 \\
110 \\
180 \\
0 \\
180\end{array}$ & $\begin{array}{l}162 \\
251 \\
416 \\
245 \\
127 \\
267 \\
166 \\
338\end{array}$ & $\begin{array}{r}15 \\
15 \\
10 \\
13 \\
7 \\
95 \\
50 \\
10\end{array}$ & $\begin{array}{r}10.8 \\
16.7 \\
41.6 \\
18.8 \\
17.4 \\
2.8 \\
3.3 \\
33.8\end{array}$ & $\begin{array}{r}72 \\
191 \\
74 \\
51 \\
69 \\
84 \\
115 \\
79\end{array}$ & $\begin{array}{l}57 \\
41 \\
16 \\
48 \\
29 \\
42 \\
52 \\
58\end{array}$ & $\begin{array}{l}1.2 \\
4.6 \\
4.6 \\
1.0 \\
2.3 \\
2.0 \\
2.2 \\
1.3\end{array}$ \\
\hline
\end{tabular}

V/L: Ventricular/lumbar ratio.

V/L In control neurological patients: for HVA <6; for 5-HIAA <3 (Bareggi unpublished; Garelis and Sourkes, 1973).

from those reported by West et al. (1972) in control neurological patients.

Table 2 also reports the findings obtained after the shunt procedure (patients 2, 3, 9, and 10). The mean values were of $287 \pm 61 \mathrm{ng} / \mathrm{ml}$ for HVA and $76 \pm 3 \mathrm{ng} / \mathrm{ml}$ for 5 -HIAA. It may be interesting to note a remarkable increase of HVA level with a concomitant drop of 5-HIAA in two of the patients in whom a comparison of the metabolites concentration found before and after surgery could be made. However the reverse was true for case 3 .

In several instances lumbar and ventricular CSF sampling were performed either simultaneously or within a few hours. The relationship between ventricular and lumbar concentration of HVA and 5-HIAA within the same subject are reported in Table 3 .
LUMBAR CSF CONCENTRATIONS OF HVA AND 5-HIAA AFTER SHUNT PROCEDURE The data obtained in the six patients examined are summarized in Table 4.

In five cases $(1,2,3,10$, and 11) an effective functioning of the shunt was proved by clinical and laboratory findings. The levels of HVA remained lower than in controls (from 7.0 to $28.0 \mathrm{ng} / \mathrm{ml}$ ) with minor variations with respect to̊ the values found in the same subjects before $T$ surgery (see cases $1,2,3$ ). No significant changes of 5-HIAA were apparent. The 5-HIAA/HVA ratio was always higher than 1 (range from 1.06 to 5.8).

In case 13 the shunt was not effective, probably because of the very low ICP $(3.9 \mathrm{~mm} \mathrm{Hg})$. In this patient the lumbar CSF levels, 136 days after surgery, were found to be $71.0 \mathrm{ng} / \mathrm{ml}$ for HVA,

TABLE 4

LUMBAR CSF HVA AND 5-HIAA CONCENTRATIONS IN NORMOTENSIVE HYDROCEPHALUS AFTER SHUNT PROCEDURE

\begin{tabular}{|c|c|c|c|c|c|c|c|c|}
\hline $\begin{array}{l}\text { Case } \\
\text { no. }\end{array}$ & $\begin{array}{l}\text { Days after } \\
\text { shunt } \\
\text { procedure }\end{array}$ & $\begin{array}{c}\text { Shunt } \\
\text { function }\end{array}$ & $\begin{array}{c}I C P \\
(m m H g)\end{array}$ & $\begin{array}{c}\text { Katzman's } \\
\text { test }\end{array}$ & $\begin{array}{c}H V A \\
(n g / m l)\end{array}$ & $\begin{array}{c}5-H I A A \\
(n g / m l)\end{array}$ & $\frac{5-H I A A}{H V A}$ & Clinical picture \\
\hline
\end{tabular}

*Days after shunt revision.

N.p.: not performed. 
and $61.0 \mathrm{ng} / \mathrm{ml}$ for 5 -HIAA with 5-HIAA/HVA ratio lower than $1(0.8)$.

An interesting pattern was observed in case 9 who, as stated above, was operated on during a worsening of the clinical picture, a month after the first hospital admission. A first control performed 30 days after the shunt (A) showed a modest clinical improvement. The lumbar CSF levels were found to be $36 \mathrm{ng} / \mathrm{ml}$ for HVA and $53 \mathrm{ng} / \mathrm{ml}$ for 5-HIAA with ratio 5-HIAA/HVA higher than 1 (1.5). These data are not comparable with those of Table 1 reporting data obtained four months before CSF shunting. In fact, at the moment of the operation both the clinical picture as well as the CSF dynamics were profoundly modified with respect to this control. A further control performed four months after the shunt procedure revealed a severe clinical worsening; the shunt was found to be obstructed. Lumbar CSF HVA level was raised to $63 \mathrm{ng} / \mathrm{ml}$, while 5-HIAA was practically unchanged (B); the ratio 5-HIAA/HVA was low (0.7). Fortythree days after the shunt revision both the clinical pictures and the biochemical parameters (C) were back to the values observed in (A). Finally, 180 days after the shunt revision, the patient was again admitted to the hospital (D) because of a new worsening of the clinical status. Intracranial pressure recording showed a very low pressure, the shunt was functioning but was not effective: the lumbar CSF levels were of $95 \mathrm{ng} / \mathrm{ml}$ for HVA and $42 \mathrm{ng} / \mathrm{ml}$ for 5-HIAA and the 5-HIAA/HVA ratio was again low (0.3).

\section{DISCUSSION}

The data reported must be considered preliminary and inadequate for definite conclusions, but sufficient for the following analysis of some aspects of normal pressure hydrocephalus.

A correlation can be appreciated, in preoperative diagnosis, between HVA lumbar CSF concentration and CSF hydrodynamics as shown by RISA. The value of the former is considerably inferior to controls $(7.5 \pm 1.26 \mathrm{ng} / \mathrm{ml}$ compared with $46.3 \pm 4.9 \mathrm{ng} / \mathrm{ml}$ mean values) whenever an alteration of CSF dynamics (slow diffusion, irregular distribution) is associated with an inversion of flow towards the ventricles, the metabolite concentration in the ventricles being within normal values. HVA lumbar con- centration, on the other hand, is superior to controls $(63.0 \pm 14.8 \mathrm{ng} / \mathrm{ml}$ compared with $46.3 \pm 4.9$ $\mathrm{ng} / \mathrm{ml}$ mean values) in cases with no evidence of flow inversion towards the ventricles, although with slow circulation and CSF stasis.

As is known (Moir et al., 1970; Curzon et al., 1971; Garelis and Sourkes, 1973) HVA enters the CSF mainly in the lateral ventricles. The inversion of the direction of CSF flow and the vicarious absorption in the lateral ventricles (Hochwald et al., 1972; Epstein et al., 1973) would reduce the diffusion of the dopamine metabolite to lower CSF spaces. This might account for the low HVA concentration at lumbar level. The hypothesis seems supported by the low HVA concentration in the lumbar CSF in all patients successfully treated with a CSF shunt. The shunt, in fact, draining fluid from the lateral ventricles, induces or further favours the inversion of CSF flow. Additional support for the above hypothesis comes from the finding of an increase of HVA concentration in the shunted patients when the shunt is obstructed.

The increased concentration of lumbar HVA is more difficult to explain. Perhaps it is related to the CSF stasis and to lack of metabolite absorption at the spinal level, where CSF absorption can occur, but in a selective way for the different CSF components (Lorenzo et al., 1970a).

There are no apparent correlations between altered CSF dynamics and CSF concentration of 5-HIAA at lumbar level. This may depend on the ubiquitous delivery of the metabolite in the CNS - that is, at cerebral as well as at spinal level (Bulat and Zivković, 1971; Curzon et al., 1971; Garelis and Sourkes, 1973).

An alternative explanation of the findings obtained is that the concentration of amine metabolites in the CSF is dependent not so much - or not only-on CSF dynamics but rather on the metabolism of amines at cerebral level. It is known that DA and 5HT metabolites in the CSF reflect concentration and turnover of such amines in specific CNS sites (Moir et al., 1970; Bulat and Zivković, 1971; Curzon et al., 1971; Garelis and Sourkes, 1973). On this basis, the finding of normal concentration of HVA in the ventricles associated with low concentration at lumbar level, in patients with reduced absorp- 
tion of CSF might indicate a decreased production of the doplamine acid metabolite. The dopaminergic systems might, in fact, be involved in the structural damage of the periventricular structures, as shown experimentally (Edvinsson et al., 1972). The occurrence of signs of Parkinsonism in some normotensive hydrocephalics (Sypert et al., 1973) would favour such a possibility. On the other hand, the increase of HVA ventricular concentration observed in some patients (cases 1 and 2) after surgical shunting might indicate a normalization of the previously damaged dopamine cerebral systems.

Our preliminary findings certainly do not provide sufficient evidence for any safe conclusion on the nature of the mechanisms responsible for the phenomena observed. However, they appear to have some practical implications. The study of HVA concentration in the lumbar CSF, in fact, seems to give a reliable indication of the occurrence or not of CSF flow inversion, that is, of a phenomenon which is generally regarded as highly significant for diagnostic purposes. Furthermore, it can provide useful information on the functioning of surgical shunting of the CSF. On such a basis, it can be usefully employed as an integrative means to support the diagnosis of normotensive hydrocephalus.

\section{REFERENCES}

Adams, R. D., Fisher, C. M., Hakim, S., Ojemann, R. G., and Sweet, W. H. (1965). Symptomatic occult hydrocephalus with 'normal' cerebrospinal-fluid pressure. A treatable syndrome. New England Journal of Medicine, 273, 117-126.

Andersson, H., and Roos, B.-E. (1966). Increased level of 5-hydroxyindoleacetic acid in cerebrospinal fluid from infantile hydrocephalus. Experientia, 22, 539-540.

Andersson, H., and Roos, B.-E. (1969). 5-hydroxyindoleacetic acid in cerebrospinal fluid of hydrocephalic children. Acta Paediatrica Scandinavica, 58, 601-608.

Bareggi, S. R., Porta, M., Selenati, A., Assael, B. M., Calderini, G., Collice, M., Rossanda, M., and Morselli, P. L. Homovanillic acid and 5-hydroxyindoleacetic acid in CSF of patients after severe head injury. (Submitted for publication.)

Bulat, M., and Zivkovič, B. (1971). Origin of 5-hydroxyindoleacetic acid in the spinal fluid. Science, 173, 738-740.

Curzon, G., Gumbert, E. J., and Sharpe, D. M. (1971). Amine metabolites in the lumbar cerebrospinal fluid of humans with restricted flow of cerebrospinal fluid. Nature, New Biology, 231, 189-191.
Edvinsson, L., Nielsen, K. C., Owman, C., Rosengren, E., and West, K. A. (1972). Concomitant fall in brain dopamine and homovanillic acid in hydrocephalic rabbits. Experimental Neurology, 37, 647-649.

Epstein, F., Hochwald, G., and Ransohoff, J. (1973). A volume control system for the treatment of hydrocephalus: laboratory and clinical experience. Journal of Neurosurgery, 38, 282-287.

Galli, G., Maira, G., Rossi, G. F., and Troncone, L. (1973). Cisternographic analysis of normotensive hydrocephalus as related to CSF dynamics. In Abstracts. XIII International Congress of Radiology, Madrid, 1973. International Congress Series No. 301. Excerpta Medica: Amsterdam.

Garelis, E., and Sourkes, T. L. (1973). Sites of origin in the central nervous system of monoamine metabolites measured in human cerebrospinal fluid. Journal of Neurology, Neurosurgery, and Psychiatry, 36, 625-629.

Hakim, S., and Adams, R. D. (1965). The special clinical problem of symptomatic hydrocephalus with normal cerebrospinal fluid pressure. Observations on cerebrospinal fluid hydrodynamics. Journal of the Neurological Sciences, 2, 307-327.

Hochwald, G. M., Lux, W. E. Jr, Sahar, A., and Ransohoff, J. (1972). Experimental hydrocephalus. Changes in cerebrospinal fluid dynamics as a function of time. Archives of Neurology, 26, 120-129.

Korf, J., Praag, H. M. van, and Sebens, J. B. (1971). Effect of intravenously administered Probenecid in humans on the levels of 5-hydroxyindoleacetic acid, homovanillic acid and 3-methoxy-4-hydroxy-phenylglycol in cerebrospinal fluid. Biochemical Pharmacology, 20, 659-668.

Lorenzo, A. V., Hammerstad, J. P., and Cutler, R. W. P. (1970a). Cerebrospinal fluid formation and absorption and transport of iodide and sulfate from the spinal subarachnoid space. Journal of the Neurological Sciences, 10, 247-258.

Lorenzo, A. V., Page, L. K., and Watters, G. V. (1970b). Relationship between cerebrospinal fluid formation, absorption and pressure in human hydrocephalus. Brain, 93, 679-692.

Moir, A. T. B., Ashcroft, G. W., Crawford, T. B. B., Eccleston, D., and Guldberg, H. C. (1970). Cerebral metabolites in cerebrospinal fluid as a biochemical approach to the brain. Brain, 93, 357-368.

Porta, M., Bareggi, S. R., Selenati, A., Assael, B. M., Beduschi, A., and Morselli, P. L. (1973). Acid monoamines metabolites in ventricular and lumbar cerebrospinal fluids of patients in post-traumatic coma. Journal of Neurosurgical Sciences, 17, 230-237.

Rossi, G. F., Galli, G., Rocco, C. di, Maira, G., Meglio, M. and Troncone, L. (1974). Normotensive hydrocephalus. The relations of pneumoencephalography and isotope cisternography to the results of surgical treatment. Acta Neurochirurgica, 30, 69-83.

Sypert, G. W., Leffman, H., and Ojemann, G. A. (1973). Occult normal pressure hydrocephalus manifested by Parkinsonism-dementia complex. Neurology (Minneap.), 23, 234-238.

West, K. A., Edvinsson, L., Nielsen, K. C., and Roos, B.-E. (1972). Concentration of acid monoamine metabolites in ventricular CSF of patients with posterior fossa tumors. In Intracranial Pressure, pp. 331-337. Edited by M. Brock, and H. Dietz. Springer: Berlin. 